\title{
Writing without words: Designing for a visual learning experience
}

\author{
Sharon Stoerger \\ School of Communication and Information, Rutgers, The State University of New Jersey, New \\ Brunswick, NJ, USA \\ E-mail: sharon.stoerger@rutgers.edu
}

Due to the large number of students, instructors teaching high enrollment courses often rely on traditional assignments such as scantron exams and research papers. While these types of assignments are functional and satisfy a purpose, they are typically not meaningful or pleasurable for students. In an introductory information technology course, the final paper was redesigned to focus on visuals rather than on written words. The redesigned visual learning experience - a digital infographic - gave students the opportunity to rely primarily on images rather than text to communicate their message about an emerging technology to an external audience. Throughout this creation process, where students had to analyze and synthesize complex information, they gained new understanding about their topic as they were thinking and making. Further, this experience had personal significance to the students - one that gave them a sense of pride and accomplishment. The students also recognized that their unique digital artifact had a life beyond the classroom, and they wanted to share their creation with others.

Keywords: Active learning, digital storytelling, infographic, pedagogy, technology, visual literacy

\section{Introduction}

Teaching and learning in a high enrollment lecture hall course can be challenging for instructors and their students. Scholars, including Dewey, Piaget, and Vygotsky, have encouraged the adoption of student-centered and active learning concepts. At the same time, instructors find the size of the class and the number of students often drives pedagogical design. The reliance on rote learning and assignments that focus on lower-order objectives, such as lectures and scantron exams, is not uncommon in large classroom settings.

While these forms of assessment are functional and reliable, they do not take learning experiences to a transformative level. Sheer memorization and regurgitation do not lead to pleasurable or meaningful experiences. In other words, these activities do not have personal significance for the students, nor do they create a memorable experience that they can apply in new contexts, use at a later time, and share with others $[1,2]$. The lack of alignment between assignments and skills utilized in practice on the job lead some students to complain about completing "busy work", as well [3].

This was the scenario for a gateway, information technology undergraduate course offered at Rutgers, The State University of New Jersey. In the past, students were 
asked to complete traditional assessments - exams and papers - but these were unfulfilling assignments for the students and instructor alike. This paper will describe the ways in which one of the assessments was transformed from a text-based written paper to a visually rich data-driven infographic and discuss the results of this redesign.

\section{Background: Designing the learning journey}

Creating opportunities that encourage and support student learning is at the heart of what instructors do. Yet, in the current education structure - one that was implemented in the $1800 \mathrm{~s}$ - the instructor often places the emphasis on lower-order thinking skills such as rote learning, memorization, and high-stakes testing [4]. Under these conditions, students may be able to perform successfully on an exam, but, because it has not been applied to a new situation, this acquired knowledge may be unusable and quickly forgotten [5].

New skills are needed to compete in the fast, and ever-changing $21^{\text {st }}$ century work environment. Unless they continue into academic employment, many students will find that they will never communicate through a mode such as a final term paper. Instead, as Brynjolfsson and McAfee argue, educational models that offer students the opportunity to engage in self-initiated, exploratory and independent learning are needed [6]. Further, in today's technology-focused world, students need to gain communication skills in genres beyond a written paper, including multimedia formats $[1,3]$.

Yet, it can be difficult for instructors to transition from traditional instructional methods to those that can be transformational to students [7]. In the case of high enrollment courses, this change may require support from instructional designers, teaching assistants, and graders. Not only do student-centered, active learning approaches require significant time, effort, and planning, but instructors also have to think differently about the course.

For the learning journey described in this paper, the instructor became a tour guide to provide support to students as they navigated this unfamiliar terrain. I asked: What type of experience through this learning journey did I want to design for my students? What did I identify as the final destination? What did I want my students to take away from this assignment once they reached the destination [8]?

\section{Envisioning the final destination: The digital infographic}

The starting point in the journey to redesign the student learning pathway required a review of the course assignments. This type of review often leads to more ideas than available resources can address, but only one was selected for the initial phase of reimagining the assignment design - the final paper. The paper required students 
to analyze and synthesize complex written text and statistical information, as well as incorporate appropriate theories into their writing. These were elements that were important to retain in this transformation process. In addition to gaining research skills, other approaches that would prepare students for the $21^{\text {st }}$ century such as digital storytelling were considered [9].

Learning activities often involve inquiry and action, but the goal was to take these concepts to the next level. Instead of writing a final paper, the assignment was redesigned as a "thingking" journey that combines thinking and making to produce a data-driven infographic [10]. The thingking process encourages students to be engaged in a topic and to create unique artifacts that convey their own voice. Instead of completing traditional assignments that had been functional, the goal was to develop a meaningful and pleasurable learning experience for students that retained the key elements associated with writing a paper - research, analysis, and synthesis.

The general topic areas covered in this web-enhanced, face-to-face gateway course were related to information technology, but the assignments did not provide opportunities for hands-on experience with technologies beyond the students' interactions with the online learning management system (LMS). Therefore, one goal was to provide an opportunity for hands-on applications. Another was to transform the final paper into a more experiential assignment that would provide students an opportunity to work with an unfamiliar visualization technology.

Several multimedia formats were considered for the redesigned assignment. In the end, PIktochart - a free, infographic tool - was selected. To complete the project, students were required to choose an emerging technology from a list provided in the course LMS. They were also guided to identify a target audience and an overarching question for inquiry. Instead of writing a paper based on the analysis and synthesis of their research on their selected topic, the students moved into the creation phase using Piktochart to communicate their findings.

Following our analogy of the learning journey as a tour to a final destination or place, it was determined that two stopping points were needed for the digital infographic project. Students would begin by putting together a proposal and sketching out their vision for the digital infographic they wanted to create. In other words, the first stopping point asked them to develop a road map for their own learning journey for this assignment. Once they received feedback on their proposal, they moved toward stopping point two, which required them to engage in the creation process. While the students were consulting text-based sources, their challenge was to think of ways to communicate that information in a visual way to an outward-facing audience.

\section{Wayfinding resources: Gear for the learning journey}

In order for students to reach the final destination and complete the infographic, they needed resources that empowered them to become immersed and engaged in 
their selected topic. They were given maps and directions (i.e., syllabus, assignment guidelines, and a rubric), as well as the tools (i.e., Piktochart, a web-based infographic application), and stops needed to successfully complete this project. Particular attention was paid to providing students with adequate structure and guidance along the way, yet, also building in enough flexibility for self-direction and self-expression. These parameters gave students the freedom to align the assignment with their professional goals and interests, as well as manage their own learning and knowledge creation processes. As students begin thinking and making, they were encouraged to explore.

\section{The learning journey}

While the digital infographic was an individual assignment, the students did not complete it alone. Through formal and informal feedback from the instructor and peers, the students were steered in certain directions and away from others. As students navigated the text-based and statistical data associated with the technology they selected, they began to draft visuals and test out ideas. During office hours, which were optional consultation sessions, they would engage in conversations about their work with the instructor. These interactions gave students the opportunity to develop their proposed idea, obtain feedback on a work-in-progress product, and deepen their understanding about their topic.

Considering the needs of external audiences, rather than submitting work that would be viewed only by their instructor, is another aspect of this journey that influenced the development of the digital artifact [11]. Students took more care in their work knowing that it had value outside of the classroom. Not only did they produce a sharable artifact that illustrated their capabilities, but they were able to apply the knowledge and skills they acquired upon completion of this journey to real world contexts such as internship and full-time employment experiences. Further, the students were able to express the results of their research in novel ways that emphasized meaningful visual communication through their infographic creation. This step in the process was about absorbing and being absorbed by their learning as they moved from lower-order to higher-order emergent understandings [12,13].

Making meaning through feedback and critique with the instructor, as well as friends and family members, is very interactive. Providing opportunities for students to exchange knowledge with others, enabled them to think, incubate, reflect, and learn differently through conversation, as well as their continued negotiations with the research materials and manipulations of the visual design [1]. For students who typically encounter traditional assessments, this can be an uncomfortable journey. This is where the instructor plays an important role as a tour guide in helping students navigate this unfamiliar terrain. 


\section{Journey challenges}

There are challenges associated with every journey, and the ones for the digital infographic assignment were no exception. Creative anxiety and fear of failure were common afflictions. Many students began with the mindset that they were not the "creative type" [14]; they didn't consider themselves to have artistic capabilities or design experience. For the digital infographic, students could not rely on text to effectively communicate their ideas; visual representations were privileged, and this was an unusual experience for many students. To students focused on grades, tackling a digital infographic project instead of a written term paper meant a risk to their project score and concerns about failing [15].

Further, Piktochart is very simple to use, which gave some students the false impression that their ability to complete the final stages of the project would be quick and easy. The complexity associated with imagining, organizing, and communicating ideas in a visual manner became clear once students began trying to construct their data-driven story using the Piktochart tool. During this design phase, students interacted with a mash-up of emotions, resources, ideas, places, artifacts, and people [16]. They learned that designing a story based on complex information without the assistance of explanatory text is challenging and entails a different approach, one that requires them to present the visual information in a sequence that helps the audience navigate the meaning [11].

\section{Reflecting on the journey}

At the end of the semester, students were asked to complete a survey about their learning journey. While many were uncomfortable navigating unfamiliar territory with what appeared to them to be an ambiguous destination, their feedback about the digital infographic project was overwhelmingly positive. They were excited about what they were able to accomplish, showed pride in the final product, and marveled at their unique visual presentation approaches. Students gained confidence in their creative capabilities along with their capacity to learn new technologies [1]. In some cases, these were skills that their "techie friends" did not even possess. Moreover, several students became immersed in their topic and continued to research it beyond the classroom context. They marveled at the ability to communicate their work through a tool such Piktochart and began to consider career opportunities in technology-related fields.

The digital infographic project was intended to produce artifacts that could be shared beyond the classroom. Students discovered that employers, members of the tech industry, and graduate program application review committees, just to name a few, wanted to learn more about their work on this project, as well as their visual communication skills. This interest by members of outside communities encouraged the students as they built and enriched their social and professional networks through 
exchanges about their digital artifacts. On the whole, the students were able to illustrate workplace competencies - intuition, practical reasoning, problem-solving, blending facts and theories - that can be opaque and hidden to potential employers.

\section{Conclusion}

William Playfair charted new ground in the late 1700s and early 1800 s when he invented ways to visualize data [17]. More than 200 years have passed since that time, yet the process of transforming complex data into a visual that is easy to comprehend can be a new adventure for students. While the course and the project are about technology, the main take-away associated with the digital infographic project was not about the technology topic or the Piktochart tool. Students were engaged in a project in which they experienced multiple ways of knowing through the making of visually-focused, externally significant, digital artifacts.

In 1938, John Dewey shared his ideas about the importance of experience in the learning process with the following, "... every experience should do something to prepare a person for later experiences of a deeper and more expansive quality" [18]. For students who reached the final destination and completed the infographic project, they recognized that they gained skills they could use in other contexts. This journey gave them the opportunity to create a digital artifact they could share with others, including employers, and develop confidence in communicating their ideas through visuals instead of words.

\section{References}

[1] Hartel J, Noone R, Oh C. The creative deliverable: A short communication. Journal of Education for Library and Information Science. 2017 Summer. 58(3): 176-183.

[2] Mayer RE. Cognitive views of creativity: Creative teaching for creative learning. Contemporary Educational Psychology. 1989. 14: 203-211. Available from: https://ac.els-cdn.com/0361476X899 00106/1-s2.0-0361476X89900106-main.pdf?_tid=ec02d56b-8e3b-4d81-9443-6204bb2802ba\& acdnat=1531840335_b81e559842fdfbe2cfb8ad823cf18f91.

[3] Dali K. The way of WalDorF: Fostering creativity in LIS programs. Journal of Documentation. 2017. 73(3): 407-431.

[4] Anderson LW, Krathwohl D. A taxonomy for learning, teaching and assessing: A revision of bloom's taxonomy of educational objectives. New York: Longman; 2001.

[5] Mayer RE. Rote versus meaningful learning. Theory into Practice. 2002. 41(4): 226-232. Available from: https://www.tandfonline.com/doi/pdf/10.1207/s15430421tip4104_4.

[6] Brynjolfsson E, McAfee A. The second machine age. New York: W. W. Norton; 2014.

[7] Craft A. Creativity in schools: Tensions and dilemmas. New York: Routledge; 2005.

[8] Wiggins GP, McTighe J. Understanding by design. Alexandria (VA): Association for Supervision and Curriculum Development; 2005.

[9] Robin BR [article on the Internet]. Digital storytelling: A powerful technology tool for the 21st century classroom. Theory into Practice. 2008 Summer. 47(3): 220-228. Available from: http:// www.jstor.org/stable/40071546.

[10] Somerson R, Hermano M, Maeda J. The art of critical making: Rhode Island School of Design on critical practice. New York: Wiley; 2013. 
[11] Coates K, Ellison A. An introduction to information design. London: Lawrence King Publishing; 2014.

[12] Boys J. Towards creative learning spaces. New York: Routledge; 2011.

[13] Lave J, Wenger E. Situated learning: Legitimate peripheral participation. Cambridge (UK): Cambridge University Press; 1991.

[14] Kelley T, Kelley D. Creative confidence: Unleashing the creative potential within us all. New York: HarperCollins; 2013.

[15] McDowell L, Sambell K. The experience of innovative assessment: Student perspectives. In: Brown S, Glasner A, eds. Assessment matters in higher education: Choosing and using diverse approaches. Philadelphia, PA: Open University Press; 2003. p. 71-82.

[16] Cavalho L, Goodyear P. The architecture of productive learning networks. New York: Routledge; 2014.

[17] Spence I. No humble pie: The origins and usage of a statistical chart. Journal of Educational and Behavioral Statistics. 2005 Winter. 30(4): 353-368. Available from: http://www.psych.utoronto.ca/ users/spence/Spence\%202005.pdf.

[18] Dewey J. Experience and education. New York: Simon \& Schuster; 1997. 